PRODUCTION OF PYRIDINE DERIVATIVES, ETC.

LXIII.-Production of Pyridine Derivatives from the Lactone of Triacetic Acid.

By N. Coltie, PhD., F.R.S.E., and W. S. Myers, B.Sc., University College, London.

IT has been long known that such substances as ethyl acetoacetate and dehydracetic acid, when treated with ammonia, yield pyridine derivatives. It was therefore expected that triacetic lactone, when treated in a similar manner, would no doubt also give a closed ring compound containing nitrogen.

That the triacetic lactone probably does yield such a compound when warmed with strong solution of ammonia has already been pointed out by one of us (Trans., 1891, 59,617), but the nature and constitution of the new compound was not then investigated. This compound was shown to be formed by a simple reaction:-

$$
\mathrm{C}_{6} \mathrm{H}_{6} \mathrm{O}_{3}+\mathrm{NH}_{3}=\mathrm{C}_{6} \mathrm{H}_{7} \mathrm{NO}_{2}+\mathrm{H}_{2} \mathrm{O} \text {. }
$$

If the action of the ammonia on triacetic lactone be similar to that 
which occurs when such substances as dimethylpyrone or coumalinic acid are warmed with ammonia, then the reaction could be expressed as follows :-<smiles>CC1=CC(=O)C(N)OC1O</smiles>

Triacetic lactone.

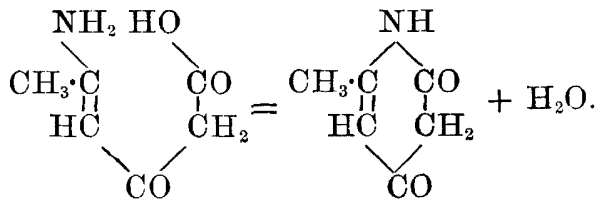

New compound.

That the reaction does occur in the above manner is rendered highly probable by the results we have obtained.

Von Pechmann has shown (Ber., 24, 3144-3153) that tautomerism undoubtedly exists in these oxygenated pyridine derivatives, and that the hydroxypyridines behave both as hydroxy-derivatives and also as compounds where the hydrogen atom of the hydroxyl group shifts to the nitrogen atom.

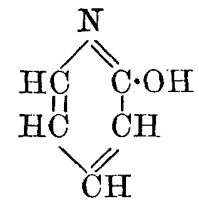

Hydroxypyridine.

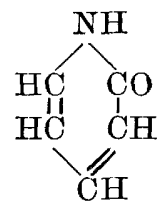

Pyridone.

The compound which we have obtained from triacetic lactone might have, therefore, either of the two following formulæ:-<smiles>C[C@@H]1CC(O)[C@H](O)[C@H]1O</smiles><smiles>CC1=CC(=O)CC1=O</smiles>

and we therefore propose to call it the $\alpha_{1} \gamma$-dihydroxy- $\alpha$-picoline. When it is treated with bromine, a dibromide is obtained :-

$$
\mathrm{C}_{6} \mathrm{H}_{7} \mathrm{NO}_{2}+\mathrm{Br}_{2}=\mathrm{C}_{6} \mathrm{H}_{7} \mathrm{NO}_{2} \cdot \mathrm{Br}_{2} \text {. }
$$

Various attempts were made to displace the oxygen by chlorine, and at first without success. If the substance is dissolved in phosphorus oxychloride, but pentachloride of phosphorus added, the reaction is very violent, and the only product which could be obtained was a very small quantity of a monochloride :-

$$
\mathrm{C}_{6} \mathrm{H}_{7} \mathrm{NO}_{2}+\mathrm{PCl}_{5}=\mathrm{C}_{6} \mathrm{H}_{6} \cdot \mathrm{NOCl}+\mathrm{HCl}+\mathrm{POCl}_{3} \text {. }
$$


Eventually, however, it was found that if oxychloride of phosphorus alone was used a dichloride was produced :-

$$
3 \mathrm{C}_{6} \mathrm{H}_{7} \mathrm{NO}_{2}+2 \mathrm{POCl}_{3}=3 \mathrm{C}_{6} \mathrm{H}_{5} \mathrm{NCl}_{2}+2 \mathrm{H}_{3} \mathrm{PO}_{4} \text {. }
$$

This dichloride possessed all the properties of a dichloropicoline, a sweet, pleasant smell, very feeble basic properties, forming an unstable double salt with chloride of platinum; whilst, when it was passed, together with hydrogen, through a tube filled with zinc-dust and heated to a low red heat, a considerable quantity of $\alpha$-picoline, b. p. $128-129^{\circ}$, was obtained :-

$$
\mathrm{C}_{6} \mathrm{H}_{5} \mathrm{NCl}_{2}+2 \mathrm{H}_{2}=\mathrm{C}_{6} \mathrm{H}_{7} \mathrm{~N}+2 \mathrm{HCl} \text {. }
$$

This proves that the original substance contains a methyl group in the $\alpha$-position relatively to the nitrogen atom. The $\alpha$-picoline, when oxidised with permanganate of potash solution, gave picolinic acid; the platinum, gold, and picric acid double salts were also prepared, but the melting points were found to be considerably higher than those noticed by former workers. In order to be certain that we were really dealing with $\alpha$-picoline, considerable trouble was taken to prepare that substance in a pure state by other known methods:-(1.) It was prepared by heating the methiodide of pyridine. This picoline gave with platinic chloride, gold chloride, and picric acid, salts with identically the same melting points and the same crystalline form as those obtained from the picoline we had prepared from the triacetic lactone. (2.) The melting points of the platinum, gold, and picric acid salts, prepared from the fraction boiling between $128^{\circ}$ and $129^{\circ}$ of the bases from bone oil, althongh not quite identical with those of the salts already prepared, were not very much lower, and certainly much higher than those given by Ladenburg and Lange.

Experimental Part.

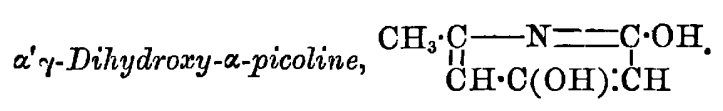

The preparation and properties of this substance have been already shortly described (loc. cit.). We have found that, even after prolonged treatment with strong ammonia, the yield is never theoretical, and that usually only 60 to 70 per cent. of the proper amount is obtained. For instance, 55 grams of the triacetic lactone gave 37 grams of the new compound.

During the purification of the crude dihydroxypicoline, by recrystallisation from very dilute acetic acid, we noticed that, on evaporation of the mother liquors, an insoluble substance always separated in voL. LXI. 
flocks having a deep blue colour. This substance resembles indigo in a most remarkable manner. It is quite insoluble in all ordinary reagents. We found that pure phenol dissolved it, when hot, to a slight extent. It is changed to a nearly colourless, pink compound when treated with strong reducing agents, but, on exposure to the air for a few seconds, the original blue substance is re-formed. Unlike indigo, it is not volatile. Uuforturately we have been quite unable to collect any large quantity of it, and owing to its great insolubility we were not able to purify it, and so are ignorant of its composition. It is always formed when the crude lactone is used, but, when pure triacetic lactone is treated with ammonia, not a trace of the blue compound could be obtained.

It is, therefore, no doubt produced from some bye-product formed, together with the triacetic lactone, by the action of sulphuric acid on dehyd racetic acid.

The prolonged action of nascent hydrogen produced from tin and hydrochloric acid was without action on the dihydroxypicoline, as even after several days action nearly the whole of the dihydroxypicoline was recovered unchanged. The oxidation by means of permanganate of potash was al:o tried, a very violent reaction occurring when permanganate of potash is added to a warm solution of dibydroxypicoline. A crystalline potassium salt was eventually obtained, but neither it nor the acid could be prepared in a state fit for analysis, so this investigation was not carried further. The dihydroxypicol ne was also heated for several hours at $150^{\circ}$ with acetyl chloride, but without result.

$$
\text { Diñydroxypicoline dillromide, } \begin{aligned}
& \mathrm{CH}_{3} \cdot \mathrm{CBr}-\mathrm{NH}=\mathrm{C} \cdot \mathrm{OH} \\
& { }_{\mathrm{CBr}} \cdot \mathrm{C}(\mathrm{OH}): \mathrm{CH}
\end{aligned} \text {. }
$$

When 5 grams of the dihydroxypicoline was dissolved in strong acetic acid, and 6.4 grams of bromine carefully added, the solution became warm. On cooling, about 8 grams of a granular salt separated. This was collected and recrystallised from hot acetic acid. It was eventually obtained in the form of white netdles melting about $220^{\circ}$ ( $226^{\circ}$ corr.) with much blackening and charring. On analysis, the following numbers were obtained:-

\section{Water of Crystallisation.}

1.5525 gram of salt lost 0.1740 gram $\mathrm{H}_{2} \mathrm{O}$ at $130^{\circ}=11.20$ per cent. $\mathrm{H}_{2} \mathrm{O}$; calculated fox $\mathrm{C}_{6} \mathrm{H}_{7} \mathrm{NO}_{2} \mathrm{Br}_{2}, 2 \mathrm{H}_{2} \mathrm{O}=11 \cdot 21$ per cent. $\mathrm{H}_{2} \mathrm{O}$. 


\section{Analysis of Dry Salt.}

I. 0.2080 gram of salt guve 0.2000 gram $\mathrm{CO}_{2}$ and 0.0392 gram $\mathrm{H}_{2} \mathrm{O}$.

II. 0.2255 gram of salt gave 0.2140 gram $\mathrm{CO}_{2}$ and $0.0425 \mathrm{gram}$ $\mathrm{H}_{\mathrm{z}} \mathrm{O}$.

III. 0.3023 gram of salt gave $13 \cdot 8$ c.c. $\mathrm{N}$ at $15^{\circ}$ and $767 \mathrm{~mm}$.

IV. 0.2848 gram of salt gave $12 \cdot 8$ c.c. $\mathrm{N}$ at $165^{\circ}$ and $767 \mathrm{~mm}$.

V. 0.350 gram of salt gave 0.4640 gram $\mathrm{AgBr}$.

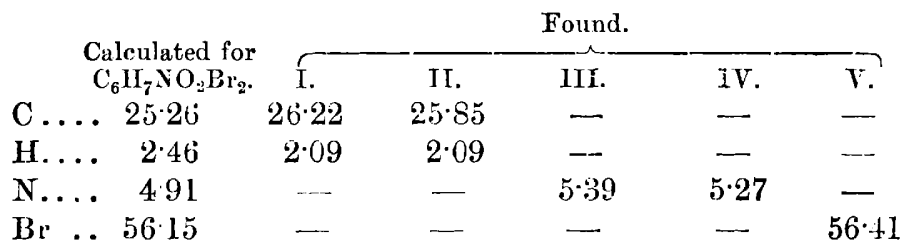

The substance, therefore, is dihydroxypicoline dibromide.

$$
\text { Dichloropicoline, } \begin{array}{r}
\mathrm{CH}_{3} \cdot \mathrm{C}-\mathrm{N}=\underset{\mathrm{C}}{\mathrm{CH}} \cdot \mathrm{Cl} \\
\mathrm{CH}
\end{array} .
$$

10 grams of the dihydroxypicoline was dissolved in phosphorus oxychluride, and 17 grams of phosphorus pentachloride added little by little, the temperature being kept at about $130^{\circ}$ by means of an oilbath. The excess of phosphorus oxychloride was then distilled off, and the pale yellow liquid left in the flask treated with water; on blowing steam through the mixture, a small quantity of an oil distilled over with the water, and from the residue about 3 grams of a crystalline compound was obtained containing chlorine. The reaction, therefore, did not seem to be a simple one, and after several experiments, only a very small amount of the oil and of the solid could be obtained. The solid, after repeated crystallisation from alcohol, melted at $170-172^{\circ}\left(173-175^{\circ}\right.$ corr.), and on analysis the substance, dried at $130^{\circ}$, gave the following figures :-

I. 0.0823 gram of substance gave 0.1515 gram $\mathrm{CO}_{2}$ and 0.0356 gram $\mathrm{H}_{2} \mathrm{O}$.

II. $0 * 2311$ gram of substance gave 0.4296 gram $\mathrm{CO}_{2}$ and 0.09:3: gram $\mathrm{H}_{2} \mathrm{O}$.

III. $0 \cdot 2757$ gram of substance gave $22 \cdot 5$ c.c. $\mathrm{N}$ at $15^{\circ}$ and $754.3 \mathrm{~mm}$. IV. 0.1087 gram of substance gave 9.0 c.c. $\mathrm{N}$ at $15^{\circ}$ and $758 \mathrm{~mm}$.

V. 0.1870 gram of substance gave $0.187 \mathrm{AgrCl}$. 


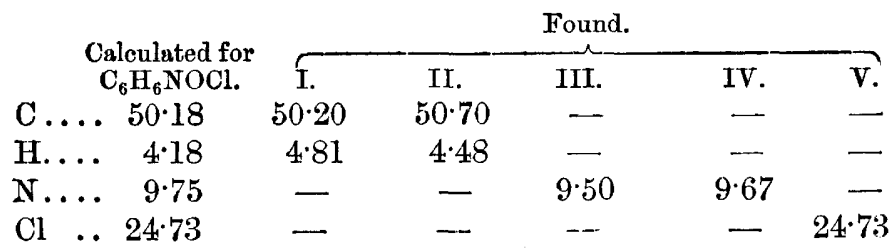

A determination of the water of crystallisation gave the following results :-

I. 0.3459 gram of substance lost 0.0392 gram $\mathrm{H}_{2} \mathrm{O}=11.34$ per cent. $\mathrm{H}_{2} \mathrm{O}$.

I1. 0.7231 gram of substance lost 0.0814 gram $\mathrm{H}_{2} \mathrm{O}=11.26$ per cent. $\mathrm{H}_{2} \mathrm{O}$.

Calculated for $\mathrm{C}_{6} \mathrm{H}_{6} \mathrm{NOClH}_{2} \mathrm{O}=11 \cdot 15$ per cent. $\mathrm{H}_{2} \mathrm{O}$.

That a monochloride should be formed in presence of a large excess of phosphorus pentachloride is not easy to explain, for we afterwards found that the oil which is produced at the same time as the monochloride was dichloropicoline, and that the only practical method for its manufacture was by boiling dihydroxypicoline with phosphorus oxychloride alone.

After many experiments had been tried with phosphorus pentachloride and dihydroxypicoline and a very large amount of the latter substance wasted, we tried the prolonged action of phosphorus oxychloride alone, and at once obtained a large quantity of the liquid dichloropicoline. It was carefully fractionated and boiled at $200-201^{\circ}\left(205-206^{\circ}\right.$ corr. $)$.

I. 0.1718 gram of substance gave 0.2797 gram $\mathrm{CO}_{2}$ and 0.0591 gram $\mathrm{H}_{2} \mathrm{O}$.

II. 0.1665 gram of substance gave 0.2701 gram $\mathrm{CO}_{2}$ and 0.0544 grain $\mathrm{H}_{2} \mathrm{O}$.

III. 0.1329 gram of substance gave 0.2170 gram $\mathrm{CO}_{2}$ and 0.0443 gram $\mathrm{H}_{2} \mathrm{O}$.

IV. 0.3785 gram of substance gave 0.6740 gram AgCl.

V. 0.2770 gram of substance gave $0.4920 \mathrm{gram} \mathrm{AgCl}$.

VI. 0.1735 gram of substance gave 13.0 c.c. $\mathrm{N}$ at $8^{\circ}$ and $754 \mathrm{~mm}$.

\begin{tabular}{|c|c|c|c|c|c|c|c|}
\hline \multirow{2}{*}{\multicolumn{2}{|c|}{$\begin{array}{l}\text { Calculated for } \\
\qquad \mathrm{C}_{6} \mathrm{H}_{5} \mathrm{NCl}_{2} \text {. }\end{array}$}} & \multicolumn{6}{|c|}{ Found. } \\
\hline & & $\mathrm{I}$ & II. & III. & IV. & V. & VI. \\
\hline C .... & $44 \cdot 44$ & $44 \cdot 40$ & $44 \cdot 24$ & $44 \cdot 53$ & - & - & - \\
\hline H... & $3 \cdot 09$ & $3 \cdot 82$ & $3 \cdot 63$ & $3 \cdot 70$ & - & - & - \\
\hline$\Gamma \ldots$ & $8 \cdot 64$ & - & -- & $\longrightarrow$ & $\longrightarrow$ & - & 8.98 \\
\hline $\mathrm{Cl}$ & $43 \cdot 82$ & - & - & - & $44: 11$ & $43 \cdot 85$ & " \\
\hline
\end{tabular}


Dichloropicoline is an oil which does not mix with water. It dissolves in strong hydrochloric acid, but is reprecipitated again on dilution. The strong hydrochloric acid solution gives an insoluble double salt with platinum chloride, which was prepared pure by first washing with hydrochloric acid, and then recrystallising from the acid. The resulting salt was dried over solid caustic soda.

I. 0.272 gram of salt gave 0.0735 gram $\mathrm{Pt}=27.02$ per cent. $\mathrm{Pt}$. II. 0.618 gram of salt gave 0.162 gram $\mathrm{Pt}=26.21$ per cent. $\mathrm{Pt}$.

Calculated for $\left(\mathrm{C}_{6} \mathrm{H}_{5} \mathrm{NCl}_{2}, \mathrm{HCl}\right)_{2} \mathrm{PtCl}_{4}=26.57$ per cent. Pt.

$$
\text { a-Picoline, } \stackrel{\mathrm{CH}_{3} \cdot \underset{\mathrm{H}}{\mathrm{CH}} \cdot \mathrm{N}: \mathrm{CH}: \mathrm{CH}}{\mathrm{C} H}
$$

The dichloride was passed together with a stream of hydrogen through a tube filled with zinc-dust and heated to a low redness. A considerable quantity of picoline was produced, which was collected by passing through hydrochloric acid solution. In order to obtain the free base, the acid solution was made alkaline with soda and distilled, the distillate extracted by shaking with ether, and the ethereal solution of picoline dried by allowing it to remain with solid potash. On fractional distillation, after the ether had passed over, the thermometer rose rapidly to $128^{\circ}$, and the whole of the remaining contents of the flask distilled between $128^{\circ}$ and $129^{\circ}$. From 15 grams of dichloropicoline, 2-3 grams of $\alpha$-picoline were obtained. It was at once converted into a platinum salt and after several recrystal. lisations was obtained in large, yellow plates which did not contain any water of crystallisation, and were found to melt at $216-217^{\circ}$ (221-222 corr.).

I. 0.3216 gram of salt gave 0.2862 gram $\mathrm{CO}_{2}$ and 0.0907 gram $\mathrm{H}_{2} \mathrm{O}$.

II. 0.3495 gram of salt gave $0 \cdot 1140$ gram Pt.
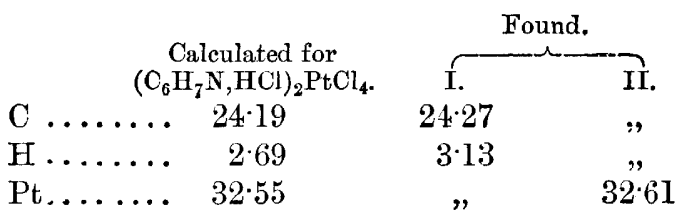

From the analysis, the substance evidently was a methylpyridine, but the melting point of the salt did not agree with that given by Ladenburg and Lange (Annalen, 247,6) as the melting point of the chloroplatinate of $\alpha$-picoline, namely, $178^{\circ}$; moreover, the salt is supposed to contain $1 \mathrm{~mol} . \mathrm{H}_{2} \mathrm{O}$. More recently, however, Stoehr 
(J. pr. Chem. [2], 42, 420-423) has given $195^{\circ}$ as the melting point, and states that when pure the salt crystallises in the anhydrons condition in monoclinic tables. We therefore thought it necessary to prepare $\alpha$-picoline by the best known methods, and compare the chloroplatinates thus formed.

The tirst method employed was heating methiodide of pyridine:-

$$
\mathrm{C}_{5} \mathrm{H}_{5} \mathrm{~N}, \mathrm{CH}_{3} \mathrm{I}=\mathrm{C}_{6} \mathrm{H}_{7} \mathrm{NHI} \text {. }
$$

a-Picoline obtained in this way distilled almost completely between $127^{\circ}$ and $129^{\circ}$, and, when converted into the chloroplatinate and purified by recrystallisation, gave a salt identical with ours in appearance and melting point. Moreover, the aurichloride was prejared from both picolines, and was found to melt at $183-184^{\circ}$

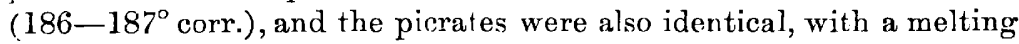
point of $169-171^{\circ}\left(172-173^{\circ}\right.$ corr. $)$. The second method employed was repeated recrystallisation of the platinichloride of a specimen of bone-oil picoline, whose boiling point lay between $128^{\circ}$ and $129^{\circ}$; after more than 20 recrystallisations, the platinum salt melted at $210-211^{\circ}\left(215-216^{\circ}\right.$ corr. $)$, but we were unable to raise the melting point further. This, however, proved that the melting points given by Stoehr, and by Ladenburg and Lange, were probably too low. The $\alpha$-picoline was also nxidised with permanganate of potash, and the picolinic acid m. p. $135-137^{\circ}$ was obtained. 